\title{
Impulsive Buying Behavior and Its Relation to the Emotional Balance
}

\author{
Anas Ramadan Ibrahim Al-Masri \\ Department of Family Reform and Guidance, The Faculty of Pedagogical Sciences, Jadara University of Excellence, Irbid, Jordan \\ Email address: \\ dranas.almasri@hotmail.com, a.almasri@jadara.edu.jo

\section{To cite this article:} \\ Anas Ramadan Ibrahim Al-Masri. Impulsive Buying Behavior and Its Relation to the Emotional Balance. International Journal of \\ Psychological and Brain Sciences. Vol. 5, No. 1, 2020, pp. 5-20. doi: 10.11648/j.ijpbs.20200501.12
}

Received: December 14, 2019; Accepted: January 6, 2020; Published: January 27, 2020

\begin{abstract}
The current study aims at introducing the relation between the impulsive buying behavior and emotional balance among the students of the Accounting Department in Petra University and Al-Imam Mohammad Ibn Saud Islamic University according to Nationality, Gender and Economic Level, through a sample consisting of (438) persons; (192) from the Accounting Department in Petra University and (246) from the Accounting Department at Al-Imam Mohammad Ibn Saud Islamic University. In order to achieve study objectives, researcher used: the impulsive buying behavior scale developed by Verplanken and Herabadi and translated by Al-Far, in addition to the emotional balance scale prepared by Dicks and translated by Al-Asmari. Study indicated negative correlation of statistical denotation between the impulsive buying behavior and the emotional balance among the students of the Accounting Department; while suggesting no differences of statistical denotation in the level of buying behavior among students depending on the variables of gender or economic level. Outcomes also concluded having differences of statistical indication in the level of emotional balance depending on nationality for the students of the Accounting Department at Al-Imam Mohammad Ibn Saud Islamic University, while not having differences of statistical denotation in the level of emotional balance in all its dimensions among students depending on the variable of gender. Study also indicated differences in the level of emotional balance among students depending on the variable of economic level between those of high economic level and those of low economic level for the benefit of those of high economic level.
\end{abstract}

Keywords: Impulsive Buying Behavior, Emotional Balance, Students of the Accounting Department

\section{Introduction}

The impulsive buying behavior is considered one of the important consumption behaviors and it holds both theoretical and practical denotations in the field of economy, psychology and consumption research [26]. Reasons and motivations of researchers from the different specializations and sciences for studying consumption patterns are varied and they include patterns such as non-regulated buying. Researchers in the field of marketing seek to understand the impulsive buying behavior to be employed for attracting consumers, while economists set their plans based on several factors including consumption patterns and their impact on economic growth and stability. In psychology; researcher is motivated to pay attention to such behaviors for studying them as a result of the conclusions and critical indicators provided by the accumulated researches in this field with regards to individuals and communities; with the most important being those related to the impacts caused by the non-regulated buying behavior in the individuals' life, nature of non-regulated buying behavior and potential of developing among individuals, along with the increasing indicators for the spread of non-regulated buying behaviors in the different societies and not being restricted to a specific community [47]. The world today has various traits that cause and facilitates such consumption behavior; for being an industrial, fast-upgrading and very impacting individuals and societies through its varied commodities and services and wide openness and communication between its different parties. A person may indicate some of the factors encouraging impulsive buying behavior to include the updates in the economic world such as the markets open for clients 24/7, shopping via TV and internet, along with the advertisements affecting individual's desire for obtaining varied commodities and services, which increases impulsive buying. There are also the cash facilities provided by the banks and 
financial institutions such as loans, credit cards and ATMs spread in all places, which facilitates immediate buying [48, 42, 41, 46, 47].

The impulsive buying behavior, which is one of the several impulsive behaviors, causes several negative impacts in each individual's life such as financial problems, feeling negative emotions such as regret, guilt and reduced self-concept, while sometimes leading to disorder in the relation between individual and relatives as a result of buying, which becomes a matter of continuous argument and criticism, while might sometimes lead to family problems such as divorce. This impulsive buying behavior mostly becomes hindrance for individuals' plans of saving for buying a house or following a specific diet for maintaining health [48, 49, 40]. Various researchers consider buyer transforming from regular buying that includes the planned commodities and shopping for entertainment, into shopping addiction with its adverse social and financial impulsive impacts [22]. Thus the impulsive buying behavior is considered a point of concern in psychology because of its impacts and outcomes that affect individuals' adaptation and psychological health.

Emotions appear as another factor that plays role in the appearance or absence of the impulsive behavior; whereas emotions interact with the cognitive and neural operations thus the impulsive behavior appearance increases whereas individual perceptions include thinking that a person can change his negative mood by being engaged in an impulsive behavior, while the individual tending to impulsive behavior reduces in case of thinking that committing an impulsive behavior would not lead to improving mood. Accordingly, being subject to emotional pressures might change the sequence of priority in individual objectives; thus the longterm objectives decline to be replaced with the immediate desires that the person recognizes contributing in improving mood [51]. Emotions; whether negative or positive, are considered the main and important part of the comprehensive and integrated growth process, including human psychological structure (conscientious system) for being related to all aspects of individual's daily living as well as special gender physiological and cognitive components along with interactive expressive behaviors that suddenly appear and hard to control [29].

The term "emotional balance" is one of the psychology terms that had several insights for discovering its true sense and uncovering its vagueness and secrets; as it is one of the indicators forhuman psychological health and extent of personality stability. Chaturvedi and Chander [20] consider emotional balance as a structure consisting of a group of components including calmness, optimism, endurance, using ration for controlling emotions and empathy with others' emotions. The most important feature of emotionally balanced individual is being capable of controlling emotions and self-control in the situations causing stimulation, while maintaining calmness, sound thinking of crisis, nonfluctuation because of insignificant stimulants, potential of bearing responsibility, fulfilling the entitled works, work stability and maintaining, avoiding violent behaviors and having emotional balance with psychological integration that connects all situation aspects and drives [33]. The state of emotional balance is never constant; even in light of the best conditions. Optimal balance is rarely achieved by any person, and when occurring it does not last. Clearly there are several negative impacts for emotions, that may affect and be affected by individual's thinking in a way that does not allow self-control, giving correct judgments and reasoning right from wrong; which affects individual's behavior, intellect and feelings. The way person is behaving and results of behavior affect the method of thinking and feeling [12]; thus there is continuous relation between individual's ideas, feelings and behavior. Since we are all consumers; we are susceptible to impulsive buying anytime we visit commercial points of sale. When types of stores increase, the impulsive buying volume increases too, since the consumer cannot resist the different temptations existing in such stores that we may even don't need, but once we enter the store we find several thinks as we are living in a society with continuous temptations [17]. Stemming from this ration; the impulsive buying behavior leads to the meaning that the desire connected to impulsiveness emerges under the pressure of the consumer emotional state; which motivates researcher for studying the role of emotional balance in consumption and in impulsive buying either as drive, interpreter or result.

\section{Study Dilemma}

The impulsive buying behavior is a non-healthy consumption behavior that is susceptible to gradual increase, and includes the potential of transforming to coercive buying behavior or addiction, while being motivated with psychological drives far from the commodities' functional need. This behavior might transform from a moderate form to another extremist one as a result of society impact and the prevailing consumption pattern $[24,25]$. The generation of youth having opportunities of wide communication and openness to the world is the most category being affected by the new consumption culture; as they are the first generation that is contemporary with such culture and they show tends to the aspire of keeping pace with it, while being the most accepting of trial and motivation, which makes them a target for marketers. As conclusion; the consumers' culture became a strong element in formulating society and individual, and the trend for spending money changed, thus it became hard to stop the international consumption standards from reaching the different areas around the world with their negative impacts to the individual and society on the psychological and financial levels; whereas such impacts vary in adversity depending on the social and economic level of individuals and society along with their gender and values. In all cases; the consumption culture might distort individuals' potential of taking rational decisions for commodity buying, and it is easy to employ buying as a mean for fulfilling the psychological and not functional drives in an incorrect and non-sound matter. There are several behavioral disorders among individuals that might have psychological roots 
resulting from the impact of emotions and personality noncompliance. When considering university students; they are the most susceptible to emotions; in light of the various situations they are facing whether at university or in family, along with the surrounding impacts that include several factors putting them in front of various problems and challenges, which motivates their emotions and causes disorder in behaviors with negative impacts on their lives [15].

Accordingly; this study comes in compliance with the psychology philosophy and objectives. In any society; psychology is concerned of providing the appropriate contribution for individuals' social and emotional growth in order to prepare them for sound citizenship and adolescence, and this may be done through acquiring the proper directions, knowledge and skills that supports them for taking sound decision and set quality life objectives. Researchers in psychology focus on the preventive aspect that is orienting individuals towards avoiding risk factors and optimally dealing with them upon facing, thus they became able to live a fruitful safe life [27].

\section{Study Significance}

The importance of the study appears through:

1) It is expected that the study outcomes would contribute in understanding the nature of relation between the impulsive buying behavior and emotional balance.

2) The study is considered important for shedding the light to the spread of the unhealthy consumption behavior in society that is internationally increasing among youth and connected to negative financial and psychological outcomes to the individuals and society, which is relatively modern field of research in the region and the entire world.

3) The current study may be provided for conducting other comparative cultural studies and other educational grades, age categories and environments.

4) Study results may be benefitting in planning and setting programs for the processes of psychological counselling and treatment among students not showing emotional balance and facing negative consumption patterns.

\section{Study Scopes}

Study is defined by the following scopes:

\subsection{Objective Scope}

The subject of impulsive buying behavior and its relation to the emotional balance among the students of the Accounting Department in Petra University and Al-Imam Mohammad Ibn Saud Islamic University, in light of nationality, gender and economic level.

\subsection{Spatial Scope}

The Accounting Department in Petra University,
Hashemite Kingdom of Jordan - Amman; and Al-Imam Mohammad Ibn Saud Islamic University - Kingdom of Saudi Arabia - Riyadh.

\subsection{Time Scope}

Determined by the date of applying study during the second semester of the academic year 2018 / 2019.

\section{Theoretical Framework}

\subsection{Impulsive Buying Behavior}

\subsubsection{Developing Researches' Concern of Impulsive Buying Behavior}

Vohs and Faber [55] provided a brief historical analysis for the development of impulsive buying behavior study, and such analysis clarifies that studying impulsive buying behavior started in the fifties and developed in concern. In their early stages; researches started by determining which are the commodities susceptible to impulsive buying? Where does it happen? In which stores that phenomenon increases? In the eighties, concern transformed to whom are the persons engaged in impulsive buying? And lastly, in following studies, questions started to be posed about when does that behavior occur among individuals and why? Variables acquiring the attention of researches varied in their relation with the impulsive buying behavior; as some studied the inner emotional state of the individual and its relation to the impulsive buying behavior, while studies focused on the previous, simultaneous and following feelings and showed a group of results for the connection between feelings and impulsive buying behavior. Another group of studies were done to understand the relation between a group of personality aspects and impulsive buying [28], and researchers found that the impulsive buying behavior is deeprooted in personality and tends to be connected to specific personality traits $[53,34]$. Additionally; several demographic factors were studied such as age category, gender, economic level, part-time jobs and pocket money.

\subsubsection{Definition of the Impulsive Buying Behavior}

Rook [48] defined impulsive buying in early stages of his researches as "buying that occurs when individual faces insisting motive for immediate purchasing, which is complicated on the sentimental level and motivates emotional struggle, leading to individual buying while disregarding results". Each of Lin and Chuang [42] along with Rook and Fisher [49] agree on that impulsive buying is: a non-planned buying that is described of several features, with the most important being that the taken decision is fact, biasing and nonobjective in evaluating the different considerations of the buying situation, while being full of feelings, without having previous intentions, and individual resistance for it is weak.

\subsubsection{Difference Between the Impulsive Buying Behavior and Ordinary Buying Behavior}

Based on the studies conducted in the field of comparison 
between the impulsive buying behavior and ordinary one, we may be reasoning some of the contradicting features; whereas Rook [48]; Rook and Fisher [49]; Burroughs [19] studies confirm that the impulsive buying behavior is full of enthusiasm and extraordinary, while the ordinary behavior is balanced and ordinary. Impulsive buying behavior has strong and committing motives contrary to the carful buying that is free of that feature; it is also quick and sudden, while ordinary buying is based on selecting. Kacen [36] confirms that the impulsive buyer is not price-sensitive and does not usually buy to obtain good deal, as the price for him is only for information and does not occupy the first element in his impulsive buying decision at store as in ordinary buying.

\subsubsection{Impulsive Buying Behavior in the Perspective of Psychological Theories}

1) Psychological Analysis Theory

Rook considers the impulsive buying behavior as the result of two fighting forces based on the principles of reality and pleasure. The principle of pleasure strongly drives individual and leads him to immediate saturation, while the principle reduces whenever the individual responds to the principle of reality and its tendency to rational thinking. Those two fighting forces compete; whereas the tendencies oriented by the principle of pleasure encourage individual for doing behavior without adequate consideration of the objective environment and its elements, and individual concern of the actual results is the least in all cases. In case the person is lacking proper restriction of tendencies; then he becomes susceptible to passing through a path that is leading him to a lot of negative psychological and social outcomes. What makes resisting such tendencies motivated by pleasure hard is that such tendencies include happy expected experiences. Although the principle of reality also seeks to providing individual with happy experiences; there is a huge difference between them, since the principle of reality directs individual towards a behavior through which he fulfills long-term objectives that delivers him to deferred saturation rather than immediate one. Transforming control over individual behavior from the principle of reality is not that easy; as it results in deep psychological struggles. It is a definitive growth development in which individuals differ in the degree of being subject to both principles and which has the most impact in their behaviors, and this discrepancy appears in the different individual behaviors including buying and consumption [48].

2) Behavioral Perspective Model

This aspect considers consumption behavior from a complete environmental perspective, and focuses on the role of external motivations in increasing the potential of various consumer behaviors; such as approaching, abstention or avoidance in buying situations. It also suggests that research in the impulsive buying behavior may be translated into clear behavioral operations. Buying behavior is defined as procedures response to a reasoning motivation that indicates the potential of having enhancers; this the potential of repeating the impulsive buying behavior varies depending on the environmental events. Environment usually includes several reasoning motivations that may be connected to some enhancers thus attracting the approach for buying; i.e. when the buyer shows impulsive buying behavior, he is doing it as a result of the reasoning environment motivations that indicate some enhancers, as the impulsive buying behavior is a procedural response that indicates having enhancers and potential of appearing depends on environmental events and its motivations [11].

3) Cognitive Aspect

Burroughs provides a cognitive theory for explaining what happens in the period of impulsive buying, and suggests that the cognitive process consists of two components, which are: first the complete cognitive processing, second the compliance between self-connotations with the things individual is facing, whereas the compliance is done with the prominent parts of self-image during the complete cognitive processing. He also considers that a lot of the impulsive buying behavior may be described as a pattern of cognitive processing, where individual recognizes having wide compliance between the nominal meaning of a commodity and the self-concept, and once that recognition takes place, there appears an immediate insisting motive that is full of strong feelings for buying commodity, and such motive will strong enough to stop any cognitive evaluative process of the buying situation and prevents from thinking of the negative results for buying [19].

\subsection{Emotional Balance}

\subsubsection{Definition of Emotional Balance}

The term of emotional balance includes two important expressions of psychology, which are balance and emotions; whereas balance (or stability) means that human has a specific volume of constant energy that tends to be equally distributed inside his body, and that volume represents the moderate state of tension inside human, while returning to the moderate state represents balance [6]. Emotions are one of the systems composing human structure in external appearance, that expresses a group of motions resulting from balance disorder and leading to aggravation of disorder thus human will be out of the moderate and sound activity and system, which indicates the term (emotion); i.e. the motion that exceeds the limits and it is one of the most important emotional aspects [52]. Younis [57] defines it as: individual potential of controlling his emotions and not aggravating emotional provocation nor following the impact of external temporary and emergent events all the way to self and social adaptation without requiring huge psychological efforts.

\subsubsection{Importance of Emotional Balance}

Emotional balance is considered one of the important aspects in human life; as it relates to individual's life and adaptation to the different life situations whether social, academic, occupational or other. Thus, individual must be adequately capable of controlling his emotions and appropriately expressing them [18]. Emotional balance helps individual in facing pressures or facilitating them with equal 
stability, abstaining from exaggeration in expressing feelings. As confirmed; individual with emotional balance has the potential for bearing delays in fulfilling his needs, and the capability of bearing reasonable extent of depression and failure, long-term planning, and is capable to bear any delay or reconsider his expectations with regards to situation requirements [3]. The person with emotional balance has traits of emotional maturity and self-confidence, stability in planning and emotions, boldly considering cases and facts without having fluctuation in temper once in a while [45]. Emotional balance is considered another aspect of the main personality aspects and an indicator for person having good psychological health, as it forms a continuous line between two points of positive pole representing emotional balance and negative pole representing neurosis (tendency to negative emotions such as anger, anxiety or depression, and sometimes indicated as emotional imbalance or contrary to emotional stability), and any person on that line while all locations are possible [56].

\subsubsection{Theories Dealing with Emotional Balance}

\section{1) The Cognitive Theory}

This theory confirms having strict relation between thinking in something and what a person feels about what he is thinking of; whereas the emotional pattern depends on the manner in which individual recognizes the situation he is facing, extend of reasoning that situation (cognitive process); i.e. emotions depend on both elements of physical motivation and cognitive classification. The theory also confirms that the emotional experience grows through individual awareness of explaining what he feels or what causes motivation using his former experience and extent of recognizing what is going on around in order interpreting his feelings. In light of that interpretation he decides how to react in the situation he is facing; thus in case of being able to control his emotions depending on the interpretation, he will be positively facing situations and will be achieving emotional balance [36].

2) Behavioral Theory

Some behavior specialists consider that emotions result from the struggle motivated for individual or the problems he is facing, which leads to committing inconsistent responses or incompliant reactions that might contribute in causing disorders in behavior and losing control over feelings, which makes him lose emotional balance; thus the theory considers emotions as resulting from the lack of control over behaviors and leads to causing problems for individual [9].

3) Ghashtelt Theory

This theory depends in explaining emotions on indicating the relation between the person having emotions and the reason for them, along with the personal role he is playing in emotions. The theory determined the changes caused to the person at the moment of emotions and his response to that change in the surrounding environment. Ghashtelt supporters express that by the collapse of limits between the emotional person's internal and external world [8].

\section{Former Studies}

\subsection{Studies Related to Studying Impulsive Buying Behavior}

Batshoun [16] issued study titled Spontaneous Buying of Shopping Commodities in the Governorate of Amman, with the objectives of determining percentage of impulsive buyers in society. Researcher used a specific scale prepared for measuring the different variables in study. She measured the impulsive buying behavior variable on that scale through posing questions related to the following: quick reaction in the buying situation, weak cognitive control in the buying situation, impact of impulsive attraction to a specific commodity while buying; which all express cognitive and emotional aspects of impulsive buying behavior. The study sample included 645 persons from Amman of both genders in different ages, marital status, level of income and academic qualification. Results indicated that persons considering themselves as spontaneous in buying form $22.5 \%$ of the sample, while the persons behaving without thinking of results from $11.2 \%$ of sample, which may be considered as practicing impulsive buying behavior. Herabadi [34] studied the impulsive buying behavior in both qualitative and quantitative studies and determined relation between the impulsive buying behavior and a group of personality aspects. The study sample included 64 female students and 13 male student of Bachelor Degree in Indonesian University, and researcher used Herabadi and Verplanken scale for measuring impulsive buying behavior translated into Indonesian, while for measuring personality aspects, the following scales were employed: need for organization scale, fear of disability scale, need for evaluation scale, need for knowledge scale and the scale of direction towards behavior in a specific situation. Results indicated having difference in the impulsive buying behavior referring to gender, whereas female students scored higher rates than male student, but the difference did not have statistical indication. In a study done by Lin and Lin [35]; they tried to discover the relation between groups of personality factors including gender with impulsive buying behavior. Study sample included 514 female and male adolescents from Taiwan with the age ranging between 1519 years. Study used a questionnaire consisting of two parts; the first includes a group of questions about some personal features such as the age, gender, pocket money, adolescents working in part-time jobs, source of family income. Whilethe second part is related to the impulsive buying behavior. Results indicated having a clear impact of gender in the level of impulsive buying behavior, whereas girls are more motivated in that behavior. Barakat [15] study aimed at recognizing the buying behavior studies in the Palestinian society and its relation to some demographic variables such as gender, age, residence, work, marital status, educational level and income, and he used for that purpose a questionnaire designed by him for determining reasons of buying behavior. Study sample consisted of 915 persons from the different Palestinian society categories in Tulkarim governorate. Results indicated that the most spending and consuming persons of the different purchases are females, 
persons between 21-40 years, university students, village residents, housewives, married and persons with high income respectively. While the least spending and consuming categories are: males, elderly, illiterate, camps' residents, traders, single, and persons of low income respectively. The sequence of aspects affecting buying behavior were as follows: factors related to product itself, external factors then personal factors, while the factors most affecting buying behavior were: product quality fulfilling individuals' needs and appropriate for their financial and social conditions. AlFar [4] study aimed at describing level of spreading impulsive buying behavior among the students of the Jordanian University of Bachelor Degree in fourth year, and exploring the impact of contradiction variables in selfconcept, financial values, and gender in studying their impulsive buying behavior. The study sample consisted of 1132 female and male student. Researcher used three scales: impulsive buying behavior scale prepared by Herabadi, financial values' scale prepared by Richens and another scale developed by researcher for measuring level of contradiction in self-concept. Results indicated that $10.2 \%$ of the sample of both genders have high level of impulsive buying behavior and there is fluctuation in the percentages of males and females obtaining score exceeding the minimum impulsive buying behavior, whereas percentage of females in the high buying behavior category was $12.9 \%$, while males was $5.8 \%$. There were also differences in the level of total impulsive buying behavior and in both cognitive and emotional aspects of impulsive buying behavior referring to gender; whereas females were most motivated for buying. Derbishi [21] study aimed at recognizing relation between the coercive buying disorder and some other psychological disorders; study sample consisted of 88 female students of King Saoud University, and for collecting data, the coercive buying scale prepared by researcher was used along with the summarized symptoms list prepared by Al-Mhareb and Naim $1424 \mathrm{H}$. Results indicated having relation with statistical denotation at the level 0.01 between coercive buying disorder and some other psychological disorders (general anxiety, depression, compulsive disorder, fear anxiety, somatization disorder, paranoia, psychosis and violence). Al-Yaseen [10] study is to identify -An impact of using social media on purchasing behavior through electronic word of mouth- Empirical study of clothing sector in Jordan, In this study,(396) respondents from different users of social media net work on the pages of who are competent clothes sellers. The researcher relied on questionnaire for the study to gather data. The study results reveal that there is an impact of using social media (awareness of social media characteristics, interaction with social media) on purchasing behavior through electronic word of mouth (both celebrities and friends about clothing sector in Jordan. The study of Barakat [14] aimed at identifying the effect of Brand on consumer's perceptions and purchase decision-making using the analytical descriptive approach. The population of this study consisted of customers of international brands famous stores in Jordan, while the sample population consisted of (85) members out of (100) which were Valid for statistical analysis. The data was collected randomly by means of a questionnaire, which was developed for this purpose. The study concluded that there is a statistically significant effect of the characteristics of the brand, brand's design and brand's symbol and on consumer perceptions and his/her purchasingdecision making. Al-Harasis [5] study aimed at identifying the effect of the appearance of celebrities in television advertising on the behavior of women in cosmetic products. The study community consisted of women who were interested in purchasing cosmetic products in the city of Amman (430) questions were answered. The study showed a number of results, the most important of which is that celebrities have a high ability to persuade women to purchase cosmetic products when they appear in television commercials. For meat and the use of celebrities (as global representatives) for cosmetic products increases women's confidence in these products. The aim of Sanad [50] study is to examine the impact of marketing using social media and its dimensions (accessibility- credibility, interaction, and skipping of advertising) on the interaction to purchases in the fashion sector in Jordan. The study population passed of the following government university female employees (Hashemite university, Al-albayt university, Al-yarmouk university and Just), and the sample size of the study was (400) employee. The study found that there is a positive and statistically significant impact of marketing dimensions using social media represented by: accessibility, interaction, skipping of advertising on the intention to purchase, and absence of a statistically impact of the credibility on the intention to purchase. Khalifa [37] Study based on the importance of the role of woman in the marketing process and aims to test the impact of using of pink marketing on the buying behavior of woman. In order to complete the study, the two elements of personal selling and advertising were adopted as independent variables while the dependent variable was the buying behavior of woman. The descriptive method and a Convenience sample of 400 units were used. The study population included women in the cosmetics market in Damascus. The study found the following results: There is a significant effect between the use of personal selling and the buying behavior of woman. There is a significant effect between the use of advertising and the buying behavior of woman.

\subsection{Studies Related to Emotional Balance}

The study of Hareesh and Al-Azab [31] aimed at recognizing level of emotional balance among employees of The mar Public University along with the denotation of differences in emotional balance among them depending on the variables of gender (males and females), type of work (doctors, technicians and administrators) and age. Sample consisted of 400 female and male employees of the hospital. Researchers used the emotional balance scale of researcher Abed A-Masoudi, whereas results indicated that the employees have intermediate level of emotional balance in general, and not having statistical differences of moral 
denotation in the level of emotional balance among employees according to the variations of gender, type of work and age. Al-Bloui [2] study aimed at discovering emotional balance and recognizing differences therein depending on the following variables: gender, marital status, age, academic qualification and communication hours with a sample of 153 social media users, and in order to fulfill objectives, researcher prepared a tool for measuring emotional balance. Study concluded that social media users have a high level of emotional balance and that there are no differences with statistical denotations in emotional balance with difference in gender, while indicating differences of statistical denotation on the emotional balance scale for the married. Denotations of statistical denotation appeared in the aspect of flexibility in dealing with life situations and total degree in the aspect of university and post-graduate aspects, while no differences of statistical denotation appeared in the emotional balance for the different communication hour's aspect. Kumar [39] conducted a study in India for indicating level of emotional balance and its relation to the social and economic level among students studying in public and private secondary schools, and in order to fulfill study objectives, the emotional balance scale was used. The study sample consisted of 100 female and male students that were selected spontaneously. Study results did not indicate differences of statistical denotation in the level of emotional balance among students studying in the public and private schools while having differences in the general rate of social and economic status of students depending on their emotional balance, whereas results indicated that the level of emotional balance among the study sample were moderate. The study of Younis [57] aimed at discovering the levels of emotional balance and self-proving and finding relation between them among a sample of students from the Jordanian University of 134 female and male students. Study concluded to having difference of statistical denotation at the level of 0.05 in emotional balance scale referred to the variable of gender for males, in addition to having positive connection relation with statistical denotation between the emotional balance and level of self-proving. It is clear from the review of former studies that there are no Arab or foreign study reviewing the relation between the variables of this one - as much as I know - since all studies discovered by the researcher are dealing with the impulsive buying behavior with other variables, or studies that handle the relation between emotional balance with other psychological variables, which gives this study a scientific value as initial methodological attempt. Alrabdaa study [7] aims to investigate the level of self-concept, emotional stability among students of King Abdullah II Excellence Secondary School, according to gender. The study also aims at investigating: the relationship between self-concept and emotional stability and identifying the predictive ability of self concept in emotional stability. The research sample included (50) students. The results of the study indicated that the students own a moderate score of self-concept. The results also revealed that there is no statistically significant difference in self-concept and emotional stability according to gender variable. There is a statistically significant correlation between self-concept and emotional stability; it also revealed that self-concept has the ability to predict about the emotional stability among students. The researcher also recommended that there is a necessity for the educational system to take in consideration, giving a school class for the basic and secondary stogies about psychology, leadership and counseling in order to make students reach an appropriate and advanced level of self concept, emotional stability, and to make students also more calm with a stable mood and better self confidence. The researcher also recommended that there should be an aware of the class activities in order to insure and emphases a high self concept that helps raising the level of emotional stability among the students. Baghdad [13] research aimed to determine the degree of prevalence of chaotic behavior and the level of emotional Stability in a sample of secondary students. Their relationship is known. Differences between the responses of the individuals in the research sample are defined on the scale of chaotic behavior and the emotional Stability scale according to the variables (gander, birth order of the student). The sample consisted of (298) students from the second secondary school in the schools of Damascus governorate. The researcher used the measure of chaotic behavior and the emotional Stability scale, which were prepared by the researcher, and adopted the research on the analytical descriptive approach. The study concluded the following results: The degree of prevalence of chaotic behavior in a sample of secondary students in the schools of Damascus governorate was at a high level, with the educational arithmetic average of the response of the members of the research sample (3.99; the level of emotional Stability in a sample of secondary students in the schools of Damascus governorate was a medium level, the educational arithmetic average of the responses of the members of the research sample (2.83); There is a statistically significant negative correlation between chaotic behavior and emotional Stability in a sample of secondary students; there were statistically significant differences between the responses of second-grade secondary students on the level of chaotic behavior according to the sex variable in favor of male students; and according to the variable birth order for students whose birth order was among their siblings; There were no statistically significant differences between the responses of secondary students on the emotional Stability scale according to the variables (gender, birth order; the regression equation indicates that the higher the chaotic behavior of the adolescent students, the lower the level of emotional Stability, because the regression coefficient value is negative, and the regression coefficient indicates that the chaotic I behavior can affect (0.020) Emotional balance of the adolescent student. The research of Ibrahim [35] objective is to identify the emotional maturity, psychological stability and social compatibility of the students of the Faculty of Physical Education and Sport Sciences as well as to identifying the relationship between psychological stability and social compatibility among students. The research 
sample consisted of (80) students second, and it was chosen by random method. One of the most important conclusions reached by the researcher is that the students enjoy emotional vigilance and psychological stability as well as social compatibility above the average. Also there is a strong correlation between emotional maturity and both psychological stability and social compatibility among students.

\section{Study Hypotheses}

1) There is relation between the impulsive buying behavior and emotional balance among the students of the Accounting Department in Petra University and AlImam Mohammad Ibn Saud Islamic University.

2) There are differences of statistical denotation between the students of the Accounting Department in Petra University and Al-Imam Mohammad Ibn Saud Islamic University in the level of buying behavior depending on the following demographic variables: (nationality: Jordanian / Saudi), (Gender: male / female), (economic level: high/ medium / low).

3) There are differences of statistical denotation between the students of the Accounting Department in Petra University and Al-Imam Mohammad Ibn Saud Islamic University in the level of emotional balance depending on the following demographic variables: (nationality: Jordanian / Saudi), (Gender: male / female), (economic level: high/ medium / low).

\section{Method and Procedures}

\subsection{Study Methodology}

The current study relied on the descriptive approach in its two aspects (correlative and comparative) to explain relation between the impulsive buying behavior and emotional balance among the students of the Accounting Department in Petra University and Al-Imam Mohammad Ibn Saud Islamic University according to Nationality, Gender and Economic Level, because they relate to the nature of the phenomenon, which depend to study reality or phenomenon as it exists with reality and care as an accurate description.

\subsection{Study Community and Sample}

Current study community represents all students of Bachelor Degree in the Accounting Department, Faculty of Financial and Administrative Sciences at Petra Jordanian University and all students of Bachelor Degree in the Accounting Department, Faculty of Economy and Administrative Sciences at Al-Imam Mohammad Ibn Saud Islamic University in their difference academic levels. The study sample consisted of ( $\mathrm{N}=438)$ female and male students, which was taken by simple spontaneous method. Study has within its variables the demographic features focusing on gender, nationality and economic level as follows:
Table 1. Distribution of study sample according to the demographic variables.

\begin{tabular}{llll}
\hline Variable & & Repetition & Percentage\% \\
\hline \multirow{3}{*}{ Gender } & Male & 254 & 58.0 \\
& Female & 184 & 42.0 \\
& Total & 438 & 100.0 \\
Nationality & Jordanian & 192 & 43.8 \\
& Saudi & 246 & 56.2 \\
& Total & 438 & 100.0 \\
economic level & High & 39 & 8.9 \\
& Medium & 362 & 82.6 \\
Total & Low & 37 & 8.4 \\
\hline
\end{tabular}

The above table indicates that $58 \%$ of total sample are males and $42 \%$ of total sample are females, that $56.2 \%$ of total sample are Saudis and $43.8 \%$ of total sample are Jordanians, and that $82.6 \%$ of total sample are level in medium economic level, while $8.9 \%$ are in high economic level and $8.4 \%$ are in low economic level.

\section{Study Tools}

\subsection{Impulsive Buying Tendency Scale}

Researcher used the Impulsive Buying scale developed by Verplanken and Herabadi [53] and translated by Al-Far [4]. Scale contained in the translated paragraphs equally divided between the cognitive aspect that includes singular paragraphs, and emotional aspect that includes the double paragraphs. He added a scale of responses for each paragraph consisting of 7 degrees, whereas degree 1 means that the paragraph does not apply to the individual while degree 7 means that it totally applies. The high degree of scale indicates high level of tendency to Impulsive Buying behavior, noting that some paragraphs, which are 1, 3, 7, 8, 9, 11, 13, 15 are corrected backwards. Researcher Al-Far checked correctness of scale by applying it to a group of students in the Pedagogical Science Faculty with total number of 168 female and male students, and the correlation between score of individual self-esteem with the score on the scale of buying behavior and the correlation coefficient was 0.93. Researcher Al-Far also checked reliability of scale using Alpha Cronbach coefficient applied on 105 female and male students from the Faculty of Pedagogical Science, and calculated reliability of consistency of the scale paragraphs according to Alpha Cronbach formula, whereas the reliability coefficient reached 0.81 . Researcher also checked reliability of scale by reapplication by applying the scale to 40 female and male students from the Jordanian University and Petra Private University and reapplied it after two weeks, and according to the testing reliability coefficient in reapplication according to Pearson formula, the reliability coefficient was 0.81 . For the purpose of this study; correctness was checked by calculating correctness of internal scale consistency through calculating the correlation coefficients between each paragraph of the scale fields and total score of the field itself as indicated in Table 2. 
Table 2. Correlation Coefficient between the score of each paragraph and total score of scale according to scale paragraphs.

\begin{tabular}{llllllll}
\hline Paragraph & $\begin{array}{l}\text { Correlation } \\
\text { coefficient }\end{array}$ & Paragraph & $\begin{array}{l}\text { Correlation } \\
\text { coefficient }\end{array}$ & Paragraph & $\begin{array}{l}\text { Correlation } \\
\text { coefficient }\end{array}$ & Paragraph & $\begin{array}{l}\text { Correlation } \\
\text { coefficient }\end{array}$ \\
\hline 1 & 0.248 & 6 & -0.054 & 11 & 0.408 & 16 & 0.205 \\
2 & 0.060 & 7 & 0.222 & 12 & 0.018 & 17 & 0.416 \\
3 & 0.247 & 8 & 0.122 & 13 & 0.056 & 18 & 0.504 \\
4 & 0.296 & 9 & 0.316 & 14 & 0.113 & 19 & 0.520 \\
5 & 0.236 & 10 & -0.086 & 15 & 0.312 & 20 & 0.456 \\
\hline
\end{tabular}

*Statistical denotation at the level of 0.05 .

The above table clarifies that the values of correlation coefficients for most scale paragraphs are positive and have statistical denotation at level 0.05 or less; which indicates that the scale paragraphs have good correctness to be accredited in conducting study. The reliability denotations were obtained through internal consistency method; whereas the Alpha Cronbach coefficient was calculated by applying scale to the explorative sample, and Alpha Cronbach coefficient of scale reached 0.657 , which is an accepted rate.

\subsection{Emotional Balance Scale}

Researcher used the Emotional Balance Scale prepared by Dicks [23] and translated by Al-Asmari [1], which included in its final edition 25 paragraphs divided into five aspects: self-awareness, emotional control, self-motivation, empathy and social skills. This scale has four answers including (highly agree, mostly agree, slightly agree, barely agree), whereas the answers scores are as follows: highly agree 4, mostly agree 3 , slightly agree 2 , barely agree 1 . Al-Asmari [1] calculated correctness of internal consistency for scale by applying it to an explorative sample of 50 students in the preparatory year at Al-Imam Mohammad Ibn Saud University, by finding the correlation coefficient between the term and total score of aspect after deleting the term. Results of internal consistency for the emotional balance scale were that all correlation coefficients ranged between $(0.692$ and 0.31 ) which indicates correct internal consistency of scale. Al-Asmari [1] checked reliability of scale in two ways: the first using Alpha Cronbach coefficient whereas the reliability reached 0.945, and the second using split-half with Spirrman Brown Coefficient for checking reliability of emotional balance that reached 0.893 . This indicates that the scale has accepted level of reliability that may be accredited in field application of study. For the purposes of this study, correctness was checked by calculating the internal consistency correctness of scale through calculating correlation coefficient between each of the scale paragraphs and the entire score or the field itself as clarified in table 3 and calculation of the structural correctness of scale clarified in table 4.

Table 3. Correlation Coefficient between the score of each paragraph and total score of scale.

\begin{tabular}{|c|c|c|c|c|c|c|c|c|c|}
\hline Paragraph & $\begin{array}{l}\text { Correlation } \\
\text { coefficient }\end{array}$ & Paragraph & $\begin{array}{l}\text { Correlation } \\
\text { coefficient }\end{array}$ & Paragraph & $\begin{array}{l}\text { Correlation } \\
\text { coefficient }\end{array}$ & Paragraph & $\begin{array}{l}\text { Correlation } \\
\text { coefficient }\end{array}$ & Paragraph & $\begin{array}{l}\text { Correlation } \\
\text { coefficient }\end{array}$ \\
\hline \multicolumn{2}{|c|}{ Self awareness } & \multicolumn{2}{|c|}{ Emotions control } & \multicolumn{2}{|c|}{ Self-motivation } & \multicolumn{2}{|l|}{ Empathy } & \multicolumn{2}{|l|}{ Social skills } \\
\hline 1 & 0.112 & 2 & 0.229 & 3 & 0.335 & 4 & 0.265 & 5 & 0176 \\
\hline 6 & 0.171 & 7 & 0.299 & 8 & 0.357 & 9 & 0.388 & 10 & 0245 \\
\hline 11 & 0.253 & 12 & 0.215 & 13 & 0.305 & 14 & 0.234 & 15 & 0.292 \\
\hline 16 & 0.341 & 17 & 0.322 & 18 & 0.291 & 19 & 0.414 & 20 & 0.325 \\
\hline 21 & 0.294 & 22 & 0.271 & 23 & 0.135 & 24 & 0.363 & 25 & 0191 \\
\hline
\end{tabular}

The above table clarifies that values of correlation coefficients for the scale paragraphs are positive and have statistical denotation at the level of 0.01 or less, which indicates that the scale paragraphs have good level of correctness that may be accredited in conducting study.

Table 4. Scale structural correctness.

\begin{tabular}{lllllll}
\hline Aspect & Self awareness & Emotions control & Self-motivation & Empathy & Social skills & Total score \\
\hline Correctness & 0.666 & 0.702 & 0.716 & 0.757 & 0.680 & 0.915 \\
\hline
\end{tabular}

Results indicate that value of correctness for all scale paragraphs was 0.915 , which means that the scale is fairly honest and appropriate for study purposes. The reliability denotations were obtained through internal consistency; as Alpha Cronbach coefficient was calculated when applying scale over the exploratory sample, and Alpha Cronbach coefficient of scale reached 0.836 , which is accepted. Table 5 below clarifies that

Table 5. Scale reliability.

\begin{tabular}{|c|c|c|c|c|c|c|}
\hline Aspect & Self awareness & Emotions control & Self-motivation & Empathy & Social skills & Total score \\
\hline Alpha Cronbach coefficient & 0.443 & 0.493 & 0.513 & 0.574 & 0.463 & 0.836 \\
\hline
\end{tabular}




\section{Study Outcomes}

For answering the first hypotheses "There is relation between the impulsive buying behavior and emotional balance in the aspects of (self-motivation, social skills and total score) among the students of the Accounting Department in Petra University and Al-Imam Mohammad Ibn Saud Islamic University”. Researcher used Pearson correlation coefficient and she will propose the following table for indicating and analyzing hypotheses results.

Table 6. Correlation coefficient between the impulsive buying behavior and emotional balance at the Accounting Department.

\begin{tabular}{|c|c|c|c|c|c|c|c|}
\hline & Aspect & $\begin{array}{l}\text { Self } \\
\text { awareness }\end{array}$ & $\begin{array}{l}\text { Emotions } \\
\text { control }\end{array}$ & $\begin{array}{l}\text { Self- } \\
\text { motivation }\end{array}$ & Empathy & Social skills & Total score \\
\hline \multirow{3}{*}{$\begin{array}{l}\text { Impulsive } \\
\text { buying } \\
\text { behavior }\end{array}$} & Pearson correlation coefficient & -.0590 & -.0650 & $-.2090 * *$ & $-.111 *$ & $-.1280 * *$ & $-.1460 * *$ \\
\hline & Denotation & .2190 & .1770 & .0000 & .0200 & .0070 & .0020 \\
\hline & Number & 438 & 438 & 438 & 438 & 438 & 438 \\
\hline
\end{tabular}

**Statistical denotation at the level of $0.01,{ }^{*}$ Statistical denotation at the level of 0.05 。

Table 6 clarifies that value of correlation coefficient between the impulsive buying behavior and emotional balance in the aspects of (self-motivation, empathy, social skills and total score) reached $(0.00,0.020,0.007,0.002)$ respectively and the potential value is less than denotation level $(0.05)$ thus there is negative correlation of statistical denotation between the impulsive buying behavior and emotional balance in the aspects of (self-motivation, empathy, social skills and total score) at the Accounting Department in Petra University and Al-Imam Mohammad Ibn Saud Islamic University. Accordingly, the hypotheses of having relation between the impulsive buying behavior and emotional balance in the aspects of (self-motivation, social skills and total score) is accepted.

Researcher refers this result to that emotional balance is one of the main elements in individual personality, which interacts with the buying behavior, and this was indicated by Habib [30] by having two of the most important aspects of individual personality, which are the emotional balance and self-control that contribute in helping individual to increase awareness of negative thoughts and imbalanced performance, whereas self-control evaluates situations for recognizing the actual reasons in a way that contributes in directing individual in the right direction and positively dealing with situations stemming from achieving emotional balance. Hasan [32] indicated that emotional balance and bearing responsibility are strictly related with several personality variables especially selfcontrol, thus researcher considers that individual has potential of buying behavior control once he has control over emotions, and through emotional balance he can control his behaviors.

For answering the second hypotheses "There are differences of statistical denotation between the students of the Accounting Department in Petra University and AlImam Mohammad Ibn Saud Islamic University in the level of buying behavior depending on the following demographic variables: (nationality: Jordanian / Saudi), (Gender: male/female), (economic level: high/ medium / low)"; T-test was used for comparing two groups (nationality: Jordanian / Saudi), (Gender: male / female) in the level of buying behavior among the students of the Accounting Department in Petra University and Al-Imam Mohammad Ibn Saud Islamic University, while (One Way Anova) test was used for comparing the averages of 3 groups in their scores on the buying behavior level scale among the students of the Accounting Department in Petra University and Al-Imam Mohammad Ibn Saud Islamic University according to the variable of (economic level: high/ medium / low).

Table 7. Results of T-test for indicating the denotation of differences in the buying behavior level among the students of the Accounting Department in Petra University and Al-Imam Mohammad Ibn Saud Islamic University according to the variable of (nationality: Jordanian / Saudi).

\begin{tabular}{lllllcc}
\hline Scale & Nationality & $\begin{array}{l}\text { Arithmetic } \\
\text { average }\end{array}$ & $\begin{array}{l}\text { Standard } \\
\text { deviation }\end{array}$ & T value & Freedom level & $\begin{array}{l}\text { Potential value } \\
\text { (sig) }\end{array}$ \\
\hline $\begin{array}{l}\text { Buying } \\
\text { behavior level }\end{array}$ & Jordanian & 3.99 & 0.60 & 3.23 & 436 & 0.00 \\
\hline
\end{tabular}

*Statistical denotation at the level of $0.01, *$ Statistical denotation at the level of 0.05 .

Table 7 indicates that the potential value of the buying behavior level was less than denotation level 0.01 , thus there are differences of statistical denotation for the buying behavior level among the students of the Accounting Department in Petra University and Al-Imam Mohammad
Ibn Saud Islamic University referring to the variable of (nationality: Jordanian / Saudi), and may say that we accept the hypotheses that "there are differences of statistical denotation in the buying behavior level referring to nationality: Jordanian / Saudi. 
Table 8. Results of T-test for indicating the denotation of differences in the buying behavior level among the students of the Accounting Department in Petra University and Al-Imam Mohammad Ibn Saud Islamic University according to the variable of (Gender: male / female).

\begin{tabular}{|c|c|c|c|c|c|c|c|}
\hline Scale & Gender & $\begin{array}{l}\text { Arithmetic } \\
\text { average }\end{array}$ & $\begin{array}{l}\text { Standard } \\
\text { deviation }\end{array}$ & T value & $\begin{array}{l}\text { Freedom } \\
\text { level }\end{array}$ & $\begin{array}{l}\text { Potential value } \\
\text { (sig) }\end{array}$ & Denotation level \\
\hline $\begin{array}{l}\text { Buying } \\
\text { behavior level }\end{array}$ & $\begin{array}{l}\text { Male } \\
\text { Female }\end{array}$ & $\begin{array}{l}3.85 \\
3.87\end{array}$ & $\begin{array}{l}0.76 \\
0.76\end{array}$ & -0.25 & 436 & 0.80 & Non-indicating \\
\hline
\end{tabular}

*Statistical denotation at the level of $0.01 *$ Statistical denotation at the level of 0.05 .

Table 8 indicates that the potential value of the buying behavior level was greater than denotation level 0.01 , thus there are no differences of statistical denotation for the buying behavior level among the students of the Accounting Department in Petra University and Al-Imam Mohammad
Ibn Saud Islamic University referring to the variable of (Gender: male/female), and may say that we reject the hypotheses that "there are differences of statistical denotation in the buying behavior level referring to (Gender: male / female).

Table 9. Results of One Way Anova test for indicating the denotation of differences in the buying behavior level among the students of the Accounting Department in Petra University and Al-Imam Mohammad Ibn Saud Islamic University according to the variable of (economic level: high/ medium / low).

\begin{tabular}{llllll}
\hline Scale & Source of different & Total boxes & Level of freedom & Average boxes & F value \\
\hline \multirow{2}{*}{ Buying behavior } & Inter-groups & 2.11 & 2 & 1.06 & 1.85 \\
level & Intra-groups & 248.89 & 435 & 0.57 & \\
& Total & 251.00 & 437 & & 0.16 \\
\hline
\end{tabular}

Table 9 indicates that the potential value of the buying behavior level was greater than denotation level 0.01 , thus there are no differences of statistical denotation for the buying behavior level among the students of the Accounting Department in Petra University and Al-Imam Mohammad Ibn Saud Islamic University referring to the variable of (economic level: high/ medium / low), and may say that we reject the hypotheses that "there are differences of statistical denotation in the buying behavior level referring to (economic level: high/ medium / low).

Results indicate that there are no differences referring to the variable of gender; i.e. gender is not considered as impact factor over the sample estimations in the impulsive buying behavior and the buying behavior is similar regardless of gender. This result is compatible with the results of Dittmar [24], that indicate absence of difference between genders in the level of impulsive buying behavior, which supports the idea of the impact for patterns determining gender behavior in increasing impulsive buying behavior among women, since focusing on such conventional patterns started to gradually reduce in some societies; thus the absence of gender impact in impulsive buying behavior in the Jordanian and Saudi societies appears to be reasonable as they are stemming from the principles of Islam and gender equality. This is also compatible with the study of Dittmar and druy [27], which indicates that absence of differences in gender in impulsive buying behavior that occurs in the situations of online shopping is expected, whereas in that situation the role of emotional scientific role for buying disappears. This results is also compliant with the study of Roberts and Martinez, which indicates having no correlation of statistical denotation between gender and impulsive buying behavior, while it is contradicting with the study of Al-Far [4] which indicates having difference in the rates of males and females obtaining score exceeding the minimum for impulsive buying behavior, whereas women were more impulsive to buying. As well as contradicting with Lin and Lin study that indicates having clear impact of gender in the level of impulsive buying behavior; whereas girls are more impulsive than boys in this behavior, in addition to Barakrat [15] study which indicates that the category of individuals with the most spending and consumption are girls. Results indicate having differences of statistical denotation in the level of buying behavior among students depending on the variable of nationality (Jordanian - Saudi) for the Saudi nationality, and researcher refers reason to the financial potentials of the Saudi youth that are higher than the Jordanian youth potentials, which is compatible with the study of Lopex and Pol, which indicates that whenever individual financial potentials increases he becomes more buying and satisfied with his living. Researcher refers reason in that Jordanian youth depend in buying on cash while the Saudi youth depend on credit cards, since depending on cash sets limit for purchases depending on the available amount while in case of using credit cards in buying from stores, then the limit increases depending on card balance.

For answering the fourth hypotheses "There are differences of statistical denotation between the students of the Accounting Department in Petra University and Al-Imam Mohammad Ibn Saud Islamic University in the level of emotional balance depending on the following demographic variables: (nationality: Jordanian / Saudi), (Gender: male / female), (economic level: high/ medium / low)"; T-test was used for comparing two groups (nationality: Jordanian / Saudi), (Gender: male / female) in the level of emotional balance among the students of the Accounting Department in Petra University and Al-Imam Mohammad Ibn Saud Islamic University, while (One Way Anova) test was used for comparing the averages of 3 groups in their scores on the emotional balance level scale among the students of the Accounting Department in Petra University and Al-Imam Mohammad Ibn Saud Islamic University according to the variable of (economic level: high/medium / low). 
Table 10. Results of T-test for indicating the denotation of differences in the emotional balance level among the students of the Accounting Department in Petra University and Al-Imam Mohammad Ibn Saud Islamic University according to the variable of (nationality: Jordanian / Saudi).

\begin{tabular}{|c|c|c|c|c|c|c|c|}
\hline Aspect & Nationality & $\begin{array}{l}\text { Arithmetic } \\
\text { average }\end{array}$ & $\begin{array}{l}\text { Standard } \\
\text { deviation }\end{array}$ & T value & Freedom level & $\begin{array}{l}\text { Potential value } \\
\text { (sig) }\end{array}$ & Denotation level \\
\hline \multirow{2}{*}{$\begin{array}{l}\text { Self } \\
\text { awareness }\end{array}$} & Jordanian & 2.44 & 0.59 & \multirow{2}{*}{-2.88} & \multirow{2}{*}{436} & \multirow{2}{*}{$* * 0.00$} & \multirow{2}{*}{ Indicating } \\
\hline & Saudi & 2.59 & 0.52 & & & & \\
\hline \multirow{2}{*}{$\begin{array}{l}\text { Emotions } \\
\text { control }\end{array}$} & Jordanian & 2.48 & 0.56 & \multirow{2}{*}{-0.79} & \multirow{2}{*}{436} & \multirow{2}{*}{0.43} & \multirow{2}{*}{ Indicating } \\
\hline & Saudi & 2.52 & 0.54 & & & & \\
\hline \multirow{2}{*}{$\begin{array}{l}\text { Self- } \\
\text { motivation }\end{array}$} & Jordanian & 2.54 & 0.59 & \multirow{2}{*}{-3.25} & \multirow{2}{*}{436} & \multirow{2}{*}{$* * 0.00$} & \multirow{2}{*}{ Indicating } \\
\hline & Saudi & 2.71 & 0.51 & & & & \\
\hline Empathy & Saudi & 2.89 & 0.56 & -3.97 & 436 & $* * 0.00$ & Indicating \\
\hline \multirow{2}{*}{ Social skills } & Jordanian & 2.60 & 0.59 & \multirow{2}{*}{-4.63} & \multirow{2}{*}{436} & \multirow{2}{*}{$* * 0.00$} & \multirow{2}{*}{ Indicating } \\
\hline & Saudi & 2.84 & 0.48 & & & & \\
\hline \multirow{2}{*}{$\begin{array}{l}\text { Emotional } \\
\text { balance } \\
\text { level }\end{array}$} & Jordanian & 2.55 & 0.49 & \multirow[b]{2}{*}{-3.99} & \multirow[b]{2}{*}{436} & \multirow[b]{2}{*}{$* * 0.00$} & \multirow[b]{2}{*}{ Indicating } \\
\hline & Saudi & 2.71 & 0.38 & & & & \\
\hline
\end{tabular}

** Statistical denotation at the level of $0.01 *$ Statistical denotation at the level of 0.05 .

Table 10 indicates that the potential value of the emotional balance level in the aspects of (self-awareness, self-motivation, empathy, social skills and total score) was less than denotation level 0.01 , thus there are differences of statistical denotation for the emotional balance level in the aspects of (self-awareness, self-motivation, empathy, social skills and total score) among the students of the Accounting Department in Petra University and Al-Imam
Mohammad Ibn Saud Islamic University referring to the variable of (nationality: Jordanian / Saudi) for Saudis, and may say that we accept the hypotheses that "there are differences of statistical denotation in the emotional balance level in the aspects of (self-awareness, selfmotivation, empathy, social skills and total score) referring to nationality: Jordanian / Saudi.

Table 11. Results of T-test for indicating the denotation of differences in the emotional balance level among the students of the Accounting Department in Petra University and Al-Imam Mohammad Ibn Saud Islamic University according to the variable of (Gender: male / female).

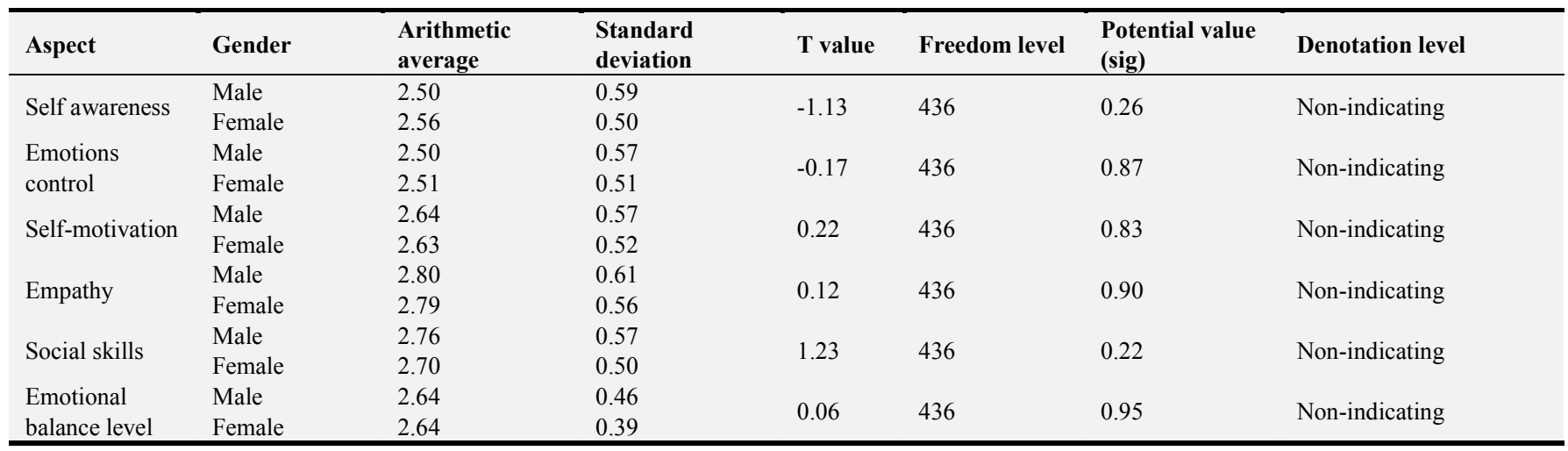

**Statistical denotation at the level of $0.01 *$ Statistical denotation at the level of 0.05 .

Table 11 indicates that the potential value of the emotional balance level was greater than denotation level 0.01 , thus there are no differences of statistical denotation for the emotional balance level among the students of the Accounting Department in Petra University and Al-Imam
Mohammad Ibn Saud Islamic University referring to the variable of (Gender: male / female), and may say that we reject the hypotheses that "there are differences of statistical denotation in the emotional balance level referring to (Gender: male / female).

Table 12. Results of One Way Anova test for indicating the denotation of differences in the emotional balance level among the students of the Accounting Department in Petra University and Al-Imam Mohammad Ibn Saud Islamic University according to the variable of (economic level: high/medium / low).

\begin{tabular}{|c|c|c|c|c|c|c|}
\hline Scale & Source of different & Total boxes & $\begin{array}{l}\text { Level of } \\
\text { freedom }\end{array}$ & $\begin{array}{l}\text { Average } \\
\text { boxes }\end{array}$ & F value & Denotation \\
\hline \multirow{3}{*}{$\begin{array}{l}\text { Self awareness } \\
\text { Emotions control }\end{array}$} & Inter-groups & 0.35 & 2 & 0.18 & \multirow[t]{3}{*}{0.56} & \multirow[t]{3}{*}{0.57} \\
\hline & Intra-groups & 135.10 & 435 & 0.31 & & \\
\hline & Total & 135.45 & 437 & & & \\
\hline \multirow{3}{*}{ Self-motivation } & Inter-groups & 0.06 & 2 & 0.03 & \multirow[t]{3}{*}{0.10} & \multirow[t]{3}{*}{0.91} \\
\hline & Intra-groups & 131.03 & 435 & 0.30 & & \\
\hline & Total & 131.09 & 437 & & & \\
\hline
\end{tabular}




\begin{tabular}{|c|c|c|c|c|c|c|}
\hline Scale & Source of different & Total boxes & $\begin{array}{l}\text { Level of } \\
\text { freedom }\end{array}$ & $\begin{array}{l}\text { Average } \\
\text { boxes }\end{array}$ & F value & Denotation \\
\hline \multirow{4}{*}{$\begin{array}{l}\text { Empathy } \\
\text { Social skills }\end{array}$} & Inter-groups & 0.24 & 2 & 0.12 & \multirow[t]{3}{*}{0.40} & \multirow[t]{3}{*}{0.67} \\
\hline & Intra-groups & 131.32 & 435 & 0.30 & & \\
\hline & Total & 131.56 & 437 & & & \\
\hline & Inter-groups & 1.72 & 2 & 0.86 & \multirow[t]{3}{*}{2.48} & \multirow[t]{3}{*}{0.08} \\
\hline \multirow[t]{8}{*}{ Emotional balance level } & Intra-groups & 150.22 & 435 & 0.36 & & \\
\hline & Total & 151.94 & 437 & & & \\
\hline & Inter-groups & 2.56 & 2 & 1.33 & \multirow[t]{3}{*}{4.54} & \multirow[t]{3}{*}{0.01} \\
\hline & Intra-groups & 126.98 & 435 & 0.29 & & \\
\hline & Total & 129.63 & 437 & & & \\
\hline & Inter-groups & 0.14 & 2 & 0.07 & \multirow[t]{3}{*}{0.38} & \multirow[t]{3}{*}{0.69} \\
\hline & Intra-groups & 82.71 & 435 & 0.19 & & \\
\hline & Total & 82.85 & 437 & & & \\
\hline
\end{tabular}

* Statistical denotation at the level of 0.05 .

Table 12 indicates that the potential value of the social skills level was less than denotation level 0.05 , thus there are differences of statistical denotation for the social skills level among the students of the Accounting Department in Petra University and Al-Imam Mohammad Ibn Saud
Islamic University referring to the variable of (economic level: high / medium / low), and may say that we accept the hypotheses that "there are differences of statistical denotation in the social skills level referring to (economic level: high / medium / low).

Table 13. Results of Scheffee Test for recognizing resources of difference according to the variance of economic level.

\begin{tabular}{llllll}
\hline Aspect & Economic level & Arithmetic average & High & Medium & Low \\
\hline \multirow{3}{*}{ Social skills } & High & 2.79 & & 0.31 \\
& Medium & 2.75 & & \\
& Low & 2.48 & & \\
\hline
\end{tabular}

*Statistical denotation at the level of 0.05 .

Table above indicates having differences of statistical denotation in the level of social skills among students of the student of Accounting Department in Petra University and Al-Imam Mohammad Ibn Saud Islamic University referring to the variable of economic level between those of high economic level and those of low economic level for the benefit of those of high economic level.

This result is compatible with the study of Harbash and Al-Azab [31] which indicates having no differences of statistical denotation in the emotional balance by difference of gender. Researcher considers this result as contradicting with the expected, whereas Al-Obaidi [6] clarified that emotional imbalance is one of the most personality aspects in which differences between genders are clarified; since males are more balanced than females in different age categories. It is also contradicting with the results of Younis [57] study in that males are more balanced. Results also indicate having differences of statistical denotation in the level of emotional balance among the students of the Accounting Department in AlImam Mohammad Ibn Saud Islamic University, and this may refer to the Saudi society norms and traditions of applying Islamic principles in daily life; as Islam calls for controlling emotions by indicating their risks to human and society life and provided the healing treatment for them. Culture provides individual with the meaning of situations in a way that enables person of obtaining the main aspects thus determining what is ordinary and what is extraordinary, what is inherent and what is not, in order to have the good values. This result may be also explained in light of the cognitive theory interpreting emotions, which indicates that the process of individual estimation and interpretation of situation depends on his knowledge and experience for the same situation, and in university life; what students are studying and situations they are facing with colleagues and others have a huge role in expanding their scope of knowledge and expertise thus affect the method of perceiving situation and quality of responding [38].

\section{Conclusion}

The current study reached many results, the most important of which are:

1) There is negative correlation of statistical denotation between the impulsive buying behavior and emotional balance in the aspects of (self-motivation, empathy, social skills and total score) at the Accounting Department in Petra University and Al-Imam Mohammad Ibn Saud Islamic University.

2) There are differences of statistical denotation for the buying behavior level among the students of the Accounting Department in Petra University and AlImam Mohammad Ibn Saud Islamic University referring to the variable of (nationality: Jordanian / Saudi.

3) There are no differences of statistical denotation for the buying behavior level among the students of the Accounting Department in Petra University and AlImam Mohammad Ibn Saud Islamic University 
referring to the variable of (Gender: male / female).

4) There are no differences of statistical denotation for the buying behavior level among the students of the Accounting Department in Petra University and AlImam Mohammad Ibn Saud Islamic University referring to the variable of (economic level: high / medium / low.

5) There are differences of statistical denotation for the emotional balance level in the aspects of (selfawareness, self-motivation, empathy, social skills and total score) among the students of the Accounting Department in Petra University and Al-Imam Mohammad Ibn Saud Islamic University referring to the variable of (nationality: Jordanian / Saudi) for Saudis.

6) There are no differences of statistical denotation for the emotional balance level among the students of the Accounting Department in Petra University and AlImam Mohammad Ibn Saud Islamic University referring to the variable of (Gender: male / female).

7) There are differences of statistical denotation for the social skills level among the students of the Accounting Department in Petra University and Al-Imam Mohammad Ibn Saud Islamic University referring to the variable of (economic level: high / medium).

8) There are differences of statistical denotation in the level of social skills among students of the student of Accounting Department in Petra University and AlImam Mohammad Ibn Saud Islamic University referring to the variable of economic level between those of high economic level and those of low economic level for the benefit of those of high economic level.

\section{Recommendations}

In light of the results, researcher suggests the following recommendations:

1) Conduct other studies on different sectors in the Jordanian, Saudi and other societies that handle different variables such as the emotional, temper, mental, cognitive and other features with their impact on individuals impulsive buying behavior.

2) Conduct study for the percentage of impulsive buying behavior spread between both genders in the Jordanian and Saudi societies.

3) Conduct studies in the future regarding the relation between the impulsive buying behavior and psychological disorders.

\section{References}

[1] Al-Asmari, S. (1437 H). Psychological Pressures and their relation to Psychological Durability and Emotional Balance among the Students of the Preparatory Year at Al-Imam Mohammad Ibn Saud Islamic University. Unpublished Master's Thesis, Al-Imam Mohammad Ibn Saud Islamic
University-Faculty of Social Sciences, Kingdom of Saudi Arabia, Riyadh.

[2] Al-Bloui, K. (2014). Emotional Balance among the Users of Social Media Websites in light of some Changes, Faculty of Pedagogy Magazine, Al-Azhar University, 157, Volume 2, 521-576.

[3] Albright S.; Terranova, M.; Honts, C.; Goedde, J.; and LaChapell, J. (2008). Perceived stress and emotional stability among working adults. Students Research Conference. 21st Annual students R Research Conference at 26/ 2/ 2008 in turman state university in kivksville.

[4] Al-Far, A. (2008). Impulsive Buying Behavior and its relation to self-concept and financial values amongst the students of fourth year at the University of Jordan. Unpublished $\mathrm{PhD}$ Thesis, University of Jordan, Jordan.

[5] Al-Harasis, A. (2018). The Impact of Celebrities Appearance of in Television Advertising on purchasing Behavior- Applied Study on women's in cosmetic products. Unpublished Master's Thesis, Amman Arab University- Faculty of Business, Amman-Jordan.

[6] Al-Obaidi, M. (1991). Measuring Emotional Balance among Martyrs' sons and relatives living with their parents, unpublished Master's Thesis, IbnRushd Faculty of Pedagogy, University of Baghdad.

[7] Alrabdaa, W. (2018). Self-Concept And Its Relationship With Emotional Stability Among Students Of King Abdullah II Excellence Secondary School In Ajloun. Educational Science Studies, 45, 1026-3713.

[8] Al-Rimawi, M. (2004), General Psychology, Amman: AlMaseera Publishing and Distribution House.

[9] Al-Sayed, M. (1998), Personality Theories, Cairo: Qeba' Publishing House.

[10] Al-Yaseen, M. (2017). An Impact of Using Social Media on Purchasing Behavior Through Electronic Word of MouthEmpirical Study of Clothing Sector in Jordan, Unpublished Master's Thesis, Middle East University- Faculty of Business, Amman, Jordan.

[11] Alzate, W. (2003). The Influences of positive reinforcement and discriminative stimuli on impulsive buying behavior: A behavior perspective model. Unpublished doctoral dissertation, University of Gulf.

[12] Arafat, F. (2009). Emotional Balance among the students of preparing female and male teachers and its relation to psychological pressures, University of Baghdad Magazine, 1 (2). 93-116.

[13] Baghdad, S. (2019). The Chaotic Behavior and its Relation to the Emotional Stability among the Students of the Third Grade Secondary Schools in Damascus Governorate. Al-Baath University Journal for Humanities, 41 (47), 37-94.

[14] Barakat, H. (2018). The Impact of Brand on Consumer's Perceptions and Purchase Decision-Making. Jerash for research and studies, 19 (10), 149-167.

[15] Barakat, Z. (2005), Shopping Psychology: Study in the Buying Behavior and its relation to some Demographic Variables in the Palestinian Community, Al-Najah University Research Magazine (Humanities), Volume 19, Edition 3, 954980. 
[16] Batshoun, D. (1994). Spontaneous Buying of Shopping Commodities, Field Study in the Governorate of Amman, unpublished Master's Thesis, University of Jordan, Amman.

[17] Bessouh. N; Iznasni. I; benhabib. A. (2015). Factors influencing impulse buying of Algerian shoppers. International Journal of Science and Research (IJSR), ISSN (Online): 2319-7064, Volume 4 Issue 3, March 2015, 860-866.

[18] Bhagate, V.; Simbak, N.; \& Hague, M. (2015). Impact of emotional stability of working men in their social adjustment of Mangalore, India, NatlJPhysiol Pharm Pharmacol, 5 (5), 14.

[19] Burroughs. J. (1996). Product symbolism, self-meaning and holistic matching; the role of information processing in impulsive buying. Advances in Consumer Research, 23, 463469.

[20] Chaturvedi, M.; Chander, R. (2012). Development of Emotional Stability Scale. Original Article, 19 (1), 37-40.

[21] Derbashi, J. (2015). Coercive Buying Disorder and its Relation to some other Psychological Disorders, Arabic Studies in Pedagogy and Psychology -KSA, (57), 341-371.

[22] Desarbo, W., Edwards, E. (1996). Typologies of compulsive buying behavior: a constrained cluster wise regression approach. Journal of Consumer Psychology, 5 (3), 231-257.

[23] Dicks, C. (2013). Evaluation of the relationship between lifestyle balance, emotional regulation, and relapse with individuals with drug and/or alcohol problems. Unpublished Master, Massey University, Albany, New Zealand.

[24] Dittmar, H. (2005a). Anew look at "Compulsive Buying": Self- discrepancies and materialistic values as predictors of compulsive buying tendency. Journal of Social Clinical Psychology, 24 (6), 832-859.

[25] Dittmar, H. (2005b). Compulsive buying- a growing Concern? An examination of gender, age, and endorsement of materialistic values as predictors. The British Journal of Psychological Society, 96, 467-491.

[26] Dittmar, H., \&Druy, J. (2000). Self-image is it in the bag. Qualitative Comparison between "ordinary" and "excessive" Consumers. Journal of Economic, Psychology, 21, 101-142.

[27] Foster, L.; Young J.; Hermann, M. (2005). The work activities of Professional School Counselors: Are the national Standards being addressed. Professional School Counseling, 8 (4), 313322 .

[28] Gardner, M.; Rook, D. (1988). Effects of impulse purchases on consumer's affective state. Advance in consumer Research, (15), 127-130.

[29] Gifford, A. (2002). Emotion and self-control, Journal of Economic Behavior \& Organization, 49, 113-130.

[30] Habeeb, M. (1996), Self-control and Creative Traits accompanying multidimensional thinking among university students, Psychology Magazine, 4 (2), 50-79.

[31] Hareesh, L.; \& Al-Azab, A. (2015). Emotional Balance among the Employees of Demur Public Hospital and its relation to some Variables, Social Studies Magazine, (46), 53-102.

[32] Hasan, A. (1989). Personality Features related to Success Scales among Teachers in the Intermediate Grade, unpublished PhD Thesis, University of Baghdad, Baghdad.
[33] Hay, I.; \& Ashman, A. (2003). The development of adolescent's emotional stability and general self-concept: the interplay of parents, peers, and gender, International Journal of Disability, Development and Education, 50 (1), 77-90.

[34] Herabadi, A. (2003). Buying Impulses: A study on impulsive consumption. Unpublished doctoral dissertation, University of Nijmegen. The Nether lands.

[35] Ibrahim, H. (2019). Emotional Maturity and its Relationship to Psychological Stability and Social Compatibility among Students of the Faculty of Physical Education and Sports Science. Journal of Physical Education Science, 12 (2), 3-11.

[36] Kenani, M. (2002). Introduction into Psychology, Beirut: AlFalah Publishing and Distribution House.

[37] Khalifa, H. (2019). The Impact of Using Pink Marketing on the Buying Behavior of Woman. Al-Baath University Journal for Humanities, 41 (71), 93-130.

[38] Khalifeh, S; Zaki,; \& Ali, N. (2009), Relation between Ambiguity and Emotional Balance among university female students, Scientific Research in Pedagogy Magazine -Egypt, 10 (131), 1-157.

[39] Kumar, P. (2013). A study of emotional stability and socioeconomic -status of students in secondary schools, International Journal of Education and Information Studies, 3 (1), 7-11.

[40] Kwak, H.; Zinkher, G.; Delorme, D.; Lavser, T. (2006). Revisiting normative influences on impulsive buying behavior and extension to compulsive buying behavior: A case from south Korea. Journal of international consumer marketing, 18 (3), 57-80.

[41] LaRose, R.; Eastin, M. (2002). Its online buying out of control? Electronic commerce and consumer Self- regulation. Journal of Broadcasting \& Electronic Media, 46 (4), 549-561.

[42] Lin, C.; Chuang, S. (2005). The effect of individual differences on adolescent's impulsive buying behavior. Adolescence, 40 (159), 551-558.

[43] Lind, C.; \& Chuang, S. (2005). The effects of individual differences on adolescents, Impulsive buying behavior. Adolescence, 40 (159), PP. 551-558.

[44] Lucas, Marger; \&Koff, Elisa. (2014). The role of impulsivity and of self- perceived attractiveness in impulse buying in women. Personality and Individual Differences, V, 56 Jan, PP. $111-115$.

[45] Pavlenko, V.; Chernyi, S.; Goubkina, D. (2009). EEG Correlates of Anxiety and Emotional Stability in Adult Healthy Subjects. Neurophysiology, 41 (5), 400-408.

[46] Roberts, J.; \& Martinez, C. (1997). The emerging consumer culture in Mexico: An exploratory investigation of compulsive buying in Mexican young adults. Journal of in International Consumer Marketing, 10 (1/2), 7-31.

[47] Roberts, J.; Jones, E. (2001). Money attitudes, credit cards, and compulsive buying among American college students. Journal of Consumer Affairs, 35 (2), pp. 213-232.

[48] Rook, D. (1987). The buying impulse. Journal of Consumer Research, 14, PP. 189-199.

[49] Rook, D.; \& Fisher, R. (1995). Normative influences on Impulsive buying behavior. Journal of Consumer Research, 22, 305-313. 
[50] Sanad, N. (2019). The Impact of Social Media Marketing on The Interaction to Purchases: A field Study on The Fashion Sector in Jordan, Unpublished Master's Thesis, Al Al-Bayt University- faculty of Economies and Administrative Sciences, Almafraq-Jordan.

[51] Schmidt, C, (2003). Impulsivity. In Coccaro, E. (Ed.), Aggression, New York: Marcel baker.

[52] Suleiman, S. (2006), Psychology and Measurement of Individual Differences, World of Books, 1st Edition, Jordan.

[53] Verplanken, B.; Herabadi, A. (2001). Individual differences in impulse buying tendency, feeling no thinking. European Journal of Personality, 15, S71-S83.
[54] Verplanken, B.; Herabadi, A.; Perry, J.; Silvera, D. (2005). Consumer style and health: The role of impulsive buying in unhealthy eating. Psychology of Health, 20 (4), 429-441.

[55] Vohs, K; Faher, R. (2003). Self-regulation and impulsive spending. Advances in Consumer Research, 30 (1), 125-126.

[56] Weinstock, L.; Whisman, M. (2006). Neuroticism as a common feature of the depressive and Anxiety disorders: A test of the revised integrative hierarchical model in a national Sample. Journal of Abnormal Psychology, 115, 68-74.

[57] Younis, M. (2005). Relation between Emotional Balance and the level of Self-actualization among sample of the University of Jordan students, Al-Najah University Research Magazine, 19 (3), 925-926. 